\title{
The Random Walk Theory And Stock Prices: Evidence From Johannesburg Stock Exchange
}

\author{
Tafadzwa T. Chitenderu, University of Fort Hare, South Africa \\ Andrew Maredza, North West University, South Africa \\ Kin Sibanda, University of Fort Hare, South Africa
}

\begin{abstract}
In this paper, we test the Johannesburg Stock Exchange market for the existence of the random walk hypothesis using monthly time series of the All Share Index (ALSI) covering the period 2000 - 2011. Traditional methods, such as unit root tests and autocorrelation test, were employed first and they all confirmed that during the period under consideration, the JSE price index followed the random walk process. In addition, the ARIMA model was constructed and it was found that the ARIMA $(1,1,1)$ was the model that most excellently fitted the data in question. Furthermore, residual tests were performed to determine whether the residuals of the estimated equation followed a random walk process in the series.
\end{abstract}

The authors found that the ALSI resembles a series that follow random walk hypothesis with strong evidence of a wide variance between forecasted and actual values, indicating little or no forecasting strength in the series. To further validate the findings in this research, the variance ratio test was conducted under heteroscedasticity and resulted in non-rejection of the random walk hypothesis. It was concluded that since the returns follow the random walk hypothesis, it can be said that JSE, in terms of efficiency, is on the weak form level and therefore opportunities of making excess returns based on out-performing the market is ruled out and is merely a game of chance.

Keywords: Random Walk Hypothesis; ARIMA; Johannesburg Stock Exchange (JSE); Variance Ratio Test

\section{INTRODUCTION}

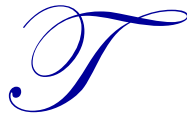

he theory of market competence (or efficiency) dominates financial literature due to the scarcity of financial resources. As such, how stock market prices behave plays a very significant part in the share of the scarce monetary resources. Market efficiency explains the relationship that exists amid information and stock price in financial markets; that is, whether or not proceeds in a market pursue a random walk process. Regulators now and again try to improve the condition of the Johannesburg Stock Exchange (JSE) by imposing different rules and regulations because price trends are important to investors and/or companies at the time when they are deciding on spreading their investment funds and risk. Stock prices also provide a benchmark against which profits on investment projects can be evaluated (Green et al., 2005). An informationally efficient market implies that capital and risks are appropriately priced without any distortions.

Following the developments in the JSE, it is necessary to add to the existing literature concerning the randomness of the All Share Index (ALSI) using current information and see if the results have changed or not. Over the years, it has become a major interest to financial analysts to come up with theories and models that explain how stock market prices behave or how they can be determined. One such model is the Random Walk Hypothesis (RWH), which is an economic theory that stipulates that prices of stocks move in accordance to a random procedure and, consequently, the prices of the stocks in the market cannot be foretold. Viney $(2007 ; 309)$ defines random walk 
hypothesis as a theory that contends that each observation in a time series, such as share prices, is dependent on the previous observation. Put differently, the hypothesis says price sequences do not demonstrate predictive patterns over a period of time but can be best described by a random walk. According to the RWH, the definite lack of correlation between the precedent and current prices can easily be seen; hence, if a share increases at a particular time, no market partaker is able to precisely foresee that it will go up again the following day (Fama, 1965).

In order to understand the RWH, it is vital to understand the theories which describe how one can predict the stock market price. There are basically two approaches, common to market professionals, which are used to predict stock prices - the chartist or technical theories and the theory of fundamental or intrinsic value analysis (Fama, 1965). The chartist theories hinges on the basic assumption that past/history repeats itself and therefore the system to forecast stock prices, as well as increase one's possible gains, is by becoming familiar with history patterns of price behaviour as well as situations of likely repetition. The fundamental or intrinsic analysts, on the other hand, hold the assumption that at every point in time, a single security has what is called an intrinsic value (equilibrium) which rests on the earnings probable of that security. Earnings potential, in turn, relies on crucial factors such as worth of management, position of the trade and the financial system, to name but a few. What this then means is that a shareholder can, through a watchful study of the fundamental factors, be able to establish whether the real price is higher than or below the intrinsic value. If real prices of stocks have a tendency of moving towards basic values, an attempt to establish this value is the same as creating predictions of prospect price which forms the heart of the analytical procedure implied by the fundamental analysis (Mishkin, 2010). In contrast, the RWH starts from the ground that the market for securities is a good example of an efficient market and in an efficient market, normal profit-maximizers actively compete and try to forecast prices. This leads to actual prices reflecting all information and becomes fine estimates of the intrinsic value of the security. According to the RWH, the dealings of numerous participants will lead to the real price of a stock wandering randomly around its intrinsic value. If the variance amid real prices and intrinsic values are methodical rather than haphazard in nature, awareness of this ought to aid intellectual market partakers to better forecast the trail through which real prices will travel toward intrinsic values. Whilst numerous clever traders try to gain using this awareness, they have a tendency of counteracting such methodical behavior in price sequence; and even though ambiguity regarding intrinsic values will stay, genuine stock prices will stroll haphazardly about their basic values (Fama, 1965). The self-determination supposition of the random-walk model is applicable as long as information of previous performance of the sequence of changes in price cannot be used to enhance anticipated gains. The implication for investment purposes is that the independence assumption acts as a sufficient explanation of actuality if actual level of reliance in series of price changes is not sufficient to create more returns than the probable proceeds under a naive buy-and-hold plan (Brooks, 2008).

The main concern of this research is to investigate the random walk hypothesis in JSE price trends. Since stock markets are important, the government, commerce, and the reserve banks of countries maintain a close look at the activities of the stock market price index. The stock market price changes now and again and sometimes a market's rise can be attributed to pure speculation or to changes in the economic variables. Hence, at times, trying to anticipate stock market movements by analyzing traditional economic and financial indicators can lead to incorrect forecasts. Put differently, the idea or assumption of price dependency or serially independent price increments is supported by the act of different investors competing in the market. If there is correlation amid different prices in different time periods, clever investors might gamble on it and override the market (arbitrage). The process of trying to outperform the market would subsequently destroy the foundation of their personal investment plan and force the correlations they utilised backside to zero. As a result, the numerical random walk model postulates that at any given instant, it is not possible to approximate where in the trade cycle an economy is and utilize such knowledge for investment purposes (Fama, 1970). As noted by Ko and Lee (1991), when the RWH holds, the weak form efficiency also holds, but the vice-versa is not true. This, then, means that the evidence supporting the random walk hypothesis can be used to also support evidence of market efficiency; however, it must be noted that infringement of the RWH must not necessarily be used as evidence of market inefficiency in the weak form.

It is against this background that this research looks at the behaviour of South Africa's stock prices and, more precisely, the independence of the South African stock market prices. The RWH says that changes in stock prices contain similar distribution and are sovereign, so a precedent tendency of a stock price cannot be effectively used to forecast its upcoming movements. Given that the authorities thrive now and again to improve the stock 
market, particularly in the areas of efficiency as an efficient stock market attracts even international investors, it becomes apparent to seek evidence for or against the random walk hypothesis of the JSE so as to determine whether it is efficient in terms of behaviour and forecastability of the stock prices. Having understood how the ALSI behaves, policymakers and regulators of the JSE may have a better understanding of the factors that may drive in the much needed capital from both local and international investors into the financial system.

\section{LITERATURE REVIEW}

RWH is an investment theory which states that market prices trail randomly up and down, lacking any power from precedent price movements, making it unfeasible to forecast with any exactness as to which route the market will go at any point (Mishkin, 2010). The RWH asserts that the path a stock's price follows is random; hence, it cannot be determined from past price information. According to Keane (1983), investors that agree with the RWH believe they cannot surpass the market unless they incur additional risk, thus to them, fundamental or technical analysis can be used fruitfully. Therefore, trying to make use of the theories will be a mere waste of time, which does not yield any extra returns.

Researches have been carried out on RWH using data from both developed countries and in developing economies with those on developed countries being prevalent. This section briefly presents various researches that have been conducted on properties of stock market prices in different countries with their various findings and conclusions. Although there have been numerous studies on whether stock markets are characterized by RWH or not, it has been shown that there still exists some inconclusiveness on the matter. This section is divided into empirical literature from developed economies, developing economies and emerging markets. It is generally acknowledged that financial markets within countries that are more developed tend to be weak-form efficient. Hence, share prices in developed markets are more inclined to follow a random walk process in comparison to developing markets.

\section{Developed Economies}

In developed economies, studies on the RWH are numerous. Kleman (2002) conducted a study to investigate market efficiency as well as the existence of random walk using indices for geographical regions of Europe, Asia, and North America. Using monthly series for the period 1983-1997, they employed the ADF and Phillips-Perron unit root test and Cochrane variance test. Their results showed that all the markets under study exhibited random walk behaviour. In addition, they further employed the non-parametric runs tests that also reached the same conclusion.

Another study was undertaken by Worthington and Higgs (2006), who examined the weak-form market efficiency of Asian equity markets. Their findings showed that no emerging markets were characterized by random walk and were therefore considered inefficient in the weak-form. However, developed markets, such as Hong Kong, New Zealand and Japan, showed consistency with RWH.

Mwamba (2011) undertook a study to investigate the predictability of stock prices in the USA and the UK. The study used daily stock prices of the S \& P 500, Dow Jones and FTSE 100 for the entire year of 2012. Their study used both parametric and non-parametric methods and the results showed that forecasts obtained from nonparametric method were nearer to actual or observed prices as compared to results obtained from the parametric model. Thus, it was concluded that both markets were characterized by predictable stock prices.

\section{Developing And Emerging Market Economies}

Evidence of random walk process in stock prices is weak in developing economies. Butler and Malaikah (1992) conducted a study in which they established the performance of separate stock returns in Saudi Arabia and Kuwait for the period 1985-1989. The serial correlation method and runs tests were employed. They concluded that Kuwait stock market price index followed the RWH, whereas the Saudi Arabia stock market showed a considerable departure from RWH. 
In Hungary, Dockery and Vergari (1996) investigated the RWH using the Budapest Stock Exchange (BSE) weekly data for the period 1991-1995. They used both homoscedastic and heteroscedastic error variances of the variance ratio tests. Their results showed evidence of the random walk.

Another study was conducted for Bahrain, Kuwait, Oman and Saudi Arabia by Dahel and Laabas (1999) for the period 1994-1998, indicating that the Kuwait market is weak-form efficient. However, only the regression test discarded the weak-form efficiency for the other three markets. When the sample was split into two sub-periods, the efficiency hypothesis was not rejected for the second sub-period in two of the markets and only by a small margin in the case of the Saudi Arabian market.

Yilmaz (2001) tested for weak-form efficiency by employing the variance-ratio-based multiple comparison test (MCT) using daily and weekly returns data for twenty-one emerging stock markets for the period 1988-2000. The results indicated that over time there was a move towards market efficiency for all the countries included in the sample. The study further showed that countries with developed stock markets and features like Japan exhibited random walk process behaviour in their stock prices. Financial crises were found to exert a negative effect on the capacity of emerging markets to efficiently price their stocks, particularly in Mexican and East Asian economies. In the case of Malaysia, the imposition of capital controls was found to cause stock prices to deviate from the random walk.

In a study of selected African stock markets, Smith et al. (2002) tested the RWH using the multiple variance test covering the period 1990-1998. Based on the obtained results, the random walk theory was discarded in all the markets, except for South Africa whose stock market was found to follow a random walk process.

Asiri (2008) applied the Dickey Fuller unit root tests and the ARIMA model, as well as exponential smoothing techniques, to measure performance of the Bahrain Stock Exchange (BSE). Their results showed evidence that stock returns followed a random walk process with no drift and trend. Ten years earlier, similar results were obtained by Khababa (1998) for the BSE.

In another research, Mobarek et al. (2008) investigated the return series on Bangladesh's Dhaka Stock Exchange (DSE) to see if they are sovereign and resemble the RWH. They used both non-parametric and parametric tests with daily data from 1988 to 2000 . Their results showed that the returns did not trail the RWH and the important auto-correlation coefficient at dissimilar lags rejected the weak-form efficiency.

In a study of Zimbabwe's Stock Exchange (ZSE), Sunde and Zivanomoyo (2008) applied the ADF unit root technique to test the random walk hypothesis using monthly data covering the period 1998-2006. Their findings indicated that ZSE stock prices were following a non-random walk process. In other words, they found previous stock prices to influence future prices.

Another study was conducted by Okpara (2010) who investigated whether or not Nigerian security prices follow a random walk. The non-parametric run test and the Ljung-Box Q-statistic where employed on annual data covering the period 1984-2006. The obtained results confirmed the Nigerian stock market to be weak-form efficient and following a random walk process.

In Bangladesh, Sharmin and Charity (2011) conducted a study to determine the level of market efficiency of the Dhaka Stock Exchange (DSE) for the period 1993-2011. Their study showed evidence that the DSE was not weak-form efficient and not following the random walk.

Empirical evidence on South Africa provides mixed results and many of these studies applied traditional methods, such as autocorrelation and unit root tests. Studies that refuted the RWH include those conducted by Jammine and Hawkins (1974), Mabhunu (2004), and Cubbin et al. (2006) while studies undertaken by Jefferis and Okeahalam (1999), Smith et al. (2002), Hamman et al. (2006), and Smith and Rodgers (2006) supported the RWH. Apart from the simplistic methodological techniques applied, the reviewed studies conducted in South Africa were undertaken in the early 2000s. It was argued that the global financial crisis may have significantly influenced the behaviour of the financial sector, particularly stock market prices. 


\section{METHODOLOGY AND DATA ANALYSIS}

The model is developed following the random walk theory presented in the preceding section. To establish whether the JSE follows a RWH, this research will modify the model developed by Box-Jenkins (1986) specified as follows:

$$
Y_{t}=\alpha_{1} Y_{t-1}+\alpha_{2} Y_{t-2}+\ldots+\alpha_{n} Y_{n-1}-\theta_{1} \varepsilon_{t-1}-\theta_{2} \varepsilon_{t-2}-\theta_{n} \varepsilon_{n-2}+\varepsilon_{t}
$$

The BJ-type time series model allows the dependent variable to be explained by its past/lagged values and the stochastic error terms (Gujarati, 2004). The model postulates that the present value of the ALSI depends linearly on the previous values of that variable plus a mixture of present and past values of white noise error terms (Brooks, 2008). In this paper, the model above is modified and specified as below:

$$
A L S I_{t}=\alpha_{1} A L S I_{t-1}+\alpha_{2} A L S I_{t-2}+\ldots+\alpha_{p} A L S I_{t-p}+\theta_{1} \varepsilon_{t}+\theta_{2} \varepsilon_{t-2} \ldots+\theta_{q} \varepsilon_{t-q}+\varepsilon_{t} .
$$

where,

ALSI $_{t}=$ All Share Index in the current period $t$

ALSI $_{\mathrm{t}-1}=$ ALSI of previous period

$\alpha=$ autoregressive parameter

$\theta=$ moving average parameter

$\varepsilon_{t}=$ error term

$\mathrm{p}=$ the number of autoregressive terms and $\mathrm{q}$ is the number of moving average terms

In order to check for robustness of the results, the stock indices are tested using four methodological approaches; namely, the Augmented Dickey Fuller (ADF) test, Correlograms, the Auto-Regressive Integrated Moving Average (ARIMA), and the Variance Ratio test (VRT). Based upon the work of Sultana and Sharmin (2011), the ADF test is traditionally used for testing randomness of price changes. The ADF is employed first in this study, followed by two autocorrelation tests - the graphical analysis (Correlogram) and the Q-statistic (Ljung-Box test). The ARIMA constitutes the authors' main methodology. In addition, the variance ratio test is also performed.

This study used monthly closing indices of the Johannesburg Stock Exchange (JSE), ALSI, covering the period 2000:1-2011:12 and generating a total of 144 observations. The ALSI is capitalization-weighted average of the market prices of all listed shares on the JSE. It is an index that shows the best signal of general market route as it encompasses shares from all sectors. It is an index figure based on the current market prices of shares (JSE, 2012). In this paper, the ALSI was used as the only variable and the series was transformed to natural logarithms.

\section{DISCUSSION OF RESULTS}

Results showed that price changes are independent, thereby leading to the conclusion that the JSE supports the RWH. Firstly, the ADF test for unit root was employed on the ALSI and results obtained showed that the critical values at $1 \%$ significant level with an intercept (-3.476472), trend and intercept (-4.023506), and none (-2.581233) are greater than their respective $t$-statistics in absolute terms, which are $-0.664657(0.8510),-1.869282(0.6652)$, and $1.903195(0.9863)$, respectively. The italicized values in parentheses represent the $\mathrm{p}$-values which were all above 0.05 , leading to non-rejection of the null hypothesis of unit root. Hence, the JSE price indices for the covered period followed a random walk process.

Having performed the autocorrelation tests, the results confirmed that the ALSI was characterized by price independence. The ACF of the series died away slowly and the PACF died away after the first lag, showing that the series was non-stationary and resembling a random walk. Also, the Q- statistics supported the fact that the JSE follows the RWH. The probability of the sum of 36 squared estimate autocorrelations coefficient was insignificant, leading to non-rejection of the null hypothesis of no autocorrelation. Therefore, it was concluded that price changes in the JSE during 2000-2011 were independent of each other. 
The Box-Jenkins's approach to time series modelling - ARIMA - was also employed in the analysis. For robustness, two ARIMA models were estimated - ARIMA (1.1.1) - see Appendix 1 - and ARIMA (2.1.2) - see Appendix 2. The model that was chosen to best suit the series was ARIMA $(1,1,1)$, and the diagnostic tests conducted on this model showed that the series under consideration exhibited trends that were random, so strongly supported the results obtained by the other test statistics. Furthermore, the outcome of the variance ratio test conducted under heteroscedasticity also confirmed the random walk behaviour of JSE stock indices (see Appendix 3). The findings were consistent with those of Bonga-Bonga (2012) who conducted a research on the JSE and confirmed weak-form efficiency using the GARCH model. Our results also conform to those of Jefferis and Okeahalam (1999), Smith et al. (2002), Hamman et al. (2006), and Smith and Rodgers (2006) who found evidence of random walk behaviour of the JSE stock prices. However, the results run contrary to the findings obtained by Jammine and Hawkins (1974), Mabhunu (2004), Cubbin et al. (2006) who found the JSE's stock price indices to be predictable.

\section{CONCLUSIONS}

In this paper, it has been established that the JSE stock prices are uncorrelated and therefore follow a random walk. This finding has major implications to investors, policymakers, and researchers which means, inter alia, that the inability to predict future stock prices implies that investors cannot beat the market trading rules. This can only be possible where there is information asymmetry. Therefore, policymakers must ensure that the stock market is continuously monitored so as to increase the level of efficiency. A number of extra measures, other than those by the JSE in improving information dissemination, can be taken into consideration. These include improving financial reporting procedures, embracing legislations and risk management measures as they are aimed at making the investors better informed, well-protected and confident. As indicated before, the efficiency of the stock market is of paramount importance to issuers of equity and portfolio investors. It has the ability to draw foreign investors and persuade home savings, thereby increasing the movement of financial capital. Analyzing the performance of stock market prices is also of importance to policymakers of any country since the stock market is the major index of economic conditions. If a market trails a random walk process, it means that prices in that market provide adequate and appropriate information and it also acts as an indicator of an efficient allocation of wealth in that country. Moreover, since the movement of stock prices is random, investors need not worry about timing the market. In this case, an investor's ability to perform the market is just about luck and not analytical skill. Investors will therefore do better with a strategy of buy-and-hold as compared to a strategy that aims at outperforming the market, as this will not succeed. Having established that the stock market price behavior is attractive, it remains necessary to try and ensure that the country has a stable environment that will aid in attracting investors. The focus of policymakers should then be on continuously improving the overall macro-economic conditions so as to maintain a desirable environment that encourages savings and investments.

\section{AUTHOR INFORMATION}

Tafadzwa Chitenderu obtained her B.Com Honours (Economics) degree, cum laude and M.Com (Economics) degree from University of Fort Hare. Her research interests are financial markets, monetary economics and econometric modelling. Email: chitenderuf@gmail.com.

Dr. Andrew Maredza is a lecturer in the School of Economic \& Decision Sciences at North-West University, South Africa. His research focus is efficiency and productivity analysis of the banking sector and its linkage with the rest of the economy, financial sustainability and financial inclusion. His other interests include financial markets, monetary economics, and applied panel and time series econometrics. He published several papers in international journals. E-mail (Corresponding Author): Andrew.Maredza@nwu.ac.za.

Kin Sibanda is a Ph.D. (Economics) student in the School of Business and Enterprise, University of Fort Hare, South Africa. E-mail: keith08.kin@gmail.com. 


\section{REFERENCES}

1. Box, E., Jenkins, G., \& Reinsel, C. (1986). Time Series Analysis: Forecasting and Control. $3^{\text {rd }}$ ed. New Jersey: Prentice Hall.

2. Brooks, C. (2008). Introductory Econometrics for Finance. $3^{\text {nd }}$ ed. UK: Cambridge University Press.

3. Bonga-Bonga, L. (2012). The Evolving Efficiency of the South African Stock Exchange, International Business \& Economics Research Journal, 11(9), pp. 60-62.

4. Butler, K. C. \& Malaikah, S. J. (1992). Efficiency and inefficiency in thinly traded stock markets: Kuwait and Saudi Arabia, Journal of Banking and Finance, 16 (1), pp. 197-210.

5. Cubbin, E., Eidne, M., Firer, C., \& Gilbert, E. (2006). Mean reversion on the JSE. Investment Analysts Journal, 63(1), pp. 1-17.

6. Dahel, R. \& Laabas, B. (1999). The Behaviour of Stock Prices in the GCC Markets. Journal of Development \& Economic Policies, 1, pp. 89-105.

7. Dockery, E. \& Vergari, F. (1996). An Investigation of the Linkages between European Union Equity Markets and Emerging Capital Markets. Managerial Finance, 27(2), pp. 40-51.

8. Fama, E. F. (1965). The behavior of stock-market prices. Journal of Business, 38 (2), pp. 34-105

9. Fama, E. (1970). Efficient Capital Markets: A Review of Theory and Empirical Work. The Journal of Finance, 25 (2), pp. 383-417.

10. Gandhi, R. (1980). Evidence of Random Walk Hypothesis in Kuwait Stock Exchange. Working Paper.

11. Green, G. H. (1988). The Effect of Inter-Regional Efficiency on Appraising Single Family Homes, The Real Estate Appraiser and Analysts, Winter.

12. Gujarati, D. N. (2004). Basic Econometrics. $4^{\text {th }}$ ed. New York: McGraw-Hill lnc.

13. Hamman, W. D., Jordaan, F., \& Smit, F. (1995). Random Walk Hypothesis: Evidence from the JSE. South African Journal of Economics, 57(1).pp 69-78.

14. Jammine, A. P. \& Hawkins, D. M. (1974). The Behavior of Some Share Indices: A Statistical Analysis. The South African Journal of Economics, 42(1), pp. 43-55.

15. Jefferis, K. \& Okeahalam C. (1999a). International Stock Market Linkages in Southern Africa. South African Journal of Accounting Research, 13(2), pp. 1-25.

16. Jefferis, K. \& Okeahalam, C. (1999b). An Event Study of the Botswana, Zimbabwe and Johannesburg Stock Exchanges. South African Journal of Business Management, 30(4), pp. 131-140.

17. JSE Securities Exchange (2003). Guidelines on the Dissemination of Price Sensitive Information. Available online. www.jse.co.za [Accessed 1 September, 2012.]

18. JSE Securities Exchange (2009). About the JSE. Available at www.jse.co.za [Accessed 11 August 2012.]

19. JSE (2012). About the JSE. Available Online. http://www.jse.co.za [Accessed: 2 April 2012].

20. JSE (2011). Summary of the Procedural Requirements of the SENS. Available On-line. www.jse.co.za [Accessed on 25 Mar, 2012].

21. Khababa, N. (1998). Behavior of Stock Prices in the Saudi Arabian Financial Market: Empirical Research Findings. Journal of Financial Management and Analysis, 11(1), pp. 48-55.

22. Keane, S. M. (1983). Efficient Markets and Financial Reporting. $1^{\text {st }}$ ed. The Institute Of Chartered Accountants of Scotland.

23. Mabhunu, M. (2004). The Market Efficiency Hypothesis And The Behaviour Of Stock Returns On The JSE Securities Exchange. Unpublished Masters' Thesis. Rhodes University.SA.

24. Mishkin, F.S. (2010). The Economics of Money, Banking and Financial Markets. $8^{\text {th }}$ ed. USA: Pearson Education International.

25. Mobarek, A. A., Mollah, S., \& Bhuyan, R. (2008). Market Efficiency in Emerging Stock Market: Evidence from Bangladesh. Journal of Emerging Market Finance, 7(1), pp. 17-41.

26. Mwamba, J. M. (2011). Modelling Stock Price Behaviour: The Kernel Approach. Journal of Economics and International Finance, 3(7), pp. 418-423.

27. Okpara, G. C. (2010). Stock Market Prices and the Random Walk Hypothesis: Further Evidence From Nigeria. Journal of Economics and International Finance, 2(3), pp. 049-057.

28. Smith, G. \& Jefferis, K. (2002). African stock markets: multiple variance ratio tests of random walks. Applied Financial Economics, 12 (4), pp. 475-484.

29. Smith, G. \& Roger, G. (2006). Variance Ratio Test of the Random Walk Hypothesis For South African Stock Futures. South African Journal of Economics, 74(3), pp 410-421. 
30. Sultana, C. \& Sharmin, S. (2011). Effeciency Measure of Capital Market: A Case of Dhaka Stock Exchange. International Journal of Business and Management, 7(1), pp. 102-108.

31. Sunde, T. \& Zivanomoyo, J. O. (2008). The Random Walk Hypothesis for the Zimbabwe Stock Exchange: January 1998-November 2006. Journal of Social Sciences, 4(3), pp. 216-221.

32. Viney, C. (2007). Financial Institutions, Instruments and Markets. $5^{\text {th }}$ ed. Australia: McGraw-Hill.

33. Worthington, A. C. \& Higgs, H. (2003). Weak-Form Market Efficiency in Asian Emerging and Developed Equity Markets: Comparative Tests of Random Walk Behaviour, University of Wollongong, Working Paper, 3, pp. 1-12.

34. Yilmaz, Z. (2001). Variance-ratio Based Multiple Comparison Test: Emerging Stock Markets. NBER Working Paper No. 9788, Boston: National Bureau of Economic Research. www.southafrica.com/stockmarket [Accessed 28/05/2012]. 


\section{APPENDIX 1}

Regression Results For ARIMA $(1,1,1)$

\begin{tabular}{|c|c|c|c|c|}
\hline Variable & Coefficient & Std. Error & t-Statistic & Prob. \\
\hline $\mathrm{C}$ & 0.004137 & 0.002103 & 1.967751 & 0.0511 \\
\hline $\operatorname{AR}(1)$ & -0.944977 & 0.019216 & -49.17726 & 0.0000 \\
\hline $\mathrm{MA}(1)$ & 0.986428 & 0.008644 & 114.1207 & 0.0000 \\
\hline R-squared & 0.058296 & Mean dependent var & & 0.004314 \\
\hline Adjusted R-squared & 0.044747 & S.D. dependent var & & 0.025107 \\
\hline S.E. of regression & 0.024538 & Akaike info criterion Schwarz & & -4.556249 \\
\hline Sum squared resid & 0.083697 & Schwarz criterion & & -4.493802 \\
\hline Log likelihood & 326.4937 & Hannan-Quinn criter. & & -4.530873 \\
\hline F-statistic & 4.302402 & Durbin-Watson stat & & 1.980862 \\
\hline Prob(F-statistic) & 0.015383 & & & \\
\hline Inverted AR Roots & -.94 & & & \\
\hline Inverted MA Roots & -.99 & & & \\
\hline
\end{tabular}

\section{APPENDIX 2}

Regression Results For ARIMA $(2,1,2)$

\begin{tabular}{lcccc}
\hline \multicolumn{1}{c}{ Variable } & Coefficient & Std. Error & t-Statistic & Prob. \\
\hline \multicolumn{1}{c}{ C } & 0.003969 & 0.002033 & 1.952521 & 0.0529 \\
AR(1) & -0.033246 & 0.029280 & -1.135451 & 0.2582 \\
AR(2) & -0.904056 & 0.028411 & -31.82078 & 0.0000 \\
MA(1) & -0.033675 & 0.023254 & -1.448150 & 0.1499 \\
MA(2) & 0.989733 & 0.010871 & 01.04242 & 0.0000 \\
\hline R-squared & 0.109830 & Mean dependent var & 0.004226 \\
Adjusted R-squared & 0.083648 & S.D. dependent var & -4.578532 \\
S.E. of regression & 0.024098 & Akaike info criterion & -4.473966 \\
Sum squared resid & 0.078979 & Schwarz criterion & -4.536040 \\
Log likelihood & 327.7865 & Hannan-Quinn criter. & 1.889112 \\
F-statistic & 4.194934 & Durbin-Watson stat & & \\
Prob(F-statistic) & 0.003104 & & & \\
\hline Inverted AR Roots & $-.02+.95 i$ & $-.02-.95 i$ & $.02-.99 i$ & \\
Inverted MA Roots & $.02+.99 \mathrm{i}$ & & & \\
\hline
\end{tabular}

\section{APPENDIX 3}

Regression Results For Variance Ratio Test

\begin{tabular}{ccccc}
\hline Joint Tests & \multicolumn{2}{c}{ Value } & df & Probability \\
\hline Max |z| (at period 16)* & & 0.505235 & 143 & 0.9777 \\
\hline $\begin{array}{c}\text { Individual Tests } \\
\text { Period }\end{array}$ & Var. Ratio & Std. Error & z-Statistic & Probability \\
\hline 2 & 0.991701 & 0.105763 & -0.078465 & 0.9375 \\
4 & 1.058904 & 0.189232 & 0.311278 & 0.7556 \\
8 & 1.140317 & 0.283120 & 0.495611 & 0.6202 \\
16 & 1.206503 & 0.408727 & 0.505235 & 0.6134
\end{tabular}

*Probability approximation using studentized maximum modulus with parameter value 4 and infinite degrees of freedom.

Test Details $($ Mean $=0.0040875771074)$

\begin{tabular}{cccc}
\hline Period & Variance & Var. Ratio & Obs. \\
\hline 1 & 0.00063 & -- & 143 \\
2 & 0.00063 & 0.99170 & 142 \\
4 & 0.00067 & 1.05890 & 140 \\
8 & 0.00072 & 1.14032 & 136 \\
16 & 0.00076 & 1.20650 & 128
\end{tabular}




\section{NOTES}

